RAD Conference Proceedings, vol. 3, pp. 103-105, 2018

ISSN 2466-4626 (online) | DOI: 10.21175/RadProc.2018.22

www.rad-proceedings.org

\title{
DETERMINATION OF TRITIUM ACTIVITY CONCENTRATION IN WATER IN THE VICINITY OF NUCLEAR FACILITIES IN SERBIA
}

\author{
Nataša Todorović1 ${ }^{*}$, Jovana Nikolov ${ }^{1}$, Ivana Stojković ${ }^{2}$, Marija Lekić3, Nataša Lazarevićc3 \\ ${ }^{1}$ University of Novi Sad, Faculty of Sciences, Department of Physics, Novi Sad, Serbia \\ ${ }^{2}$ University of Novi Sad, Faculty of Technical Sciences, Novi Sad, Serbia \\ 3Public Company "Nuclear Facilities of Serbia", Belgrade, Serbia
}

\begin{abstract}
Tritium is produced naturally, mainly through interactions of cosmic rays with nitrogen in the atmosphere. Human activities (including thermonuclear bomb tests, operation of nuclear reactors, manufacture of nuclear weapons, and various industrial and medical applications) are also sources of tritium. Once in the environment, tritium occurs mainly in the form of tritiated water (HTO). International legislations and national regulations are in place to impose tight controls on releases as well as to ensure regular monitoring near anthropogenic sources. Tritium monitoring of surface and well waters that supply populations with drinking water are of particular importance. The monitoring data are used to trace releases and also for the evaluation of tritium doses to nearby residents. According to the European Commission, the upper limit for tritium in water is $100 B q l^{-1}$ [1]. This value was not set based on the probability of health effects. It is a monitoring tool (action level) because tritium activity concentration exceeding $100 \mathrm{Bql} \mathrm{l}^{-1}$ could indicate a leakage or a release for which further analysis, to check if other radionuclides are present in water, would be warranted. In this paper, tritium concentrations measured in water samples collected from the Mlaka creek in the vicinity of the "Nuclear Facilities of Serbia" are presented.
\end{abstract}

Key words: Tritium, Liquid Scintillation Counting, monitoring, health effects

\section{INTRODUCTION}

Tritium is a radioactive isotope of hydrogen with a physical half-life of $4500 \pm 8$ days that behaves like stable hydrogen and is usually found attached to molecules replacing hydrogen. This radioactive isotope is directly incorporated into water molecules as $\mathrm{H} 3 \mathrm{HO}$ (HTO). This radionuclide occurs naturally and is also originating from anthropogenic sources. Natural tritium is produced in the atmosphere from the interaction of cosmic radiation with atmospheric nitrogen [2]. Anthropogenic production is adding to the natural background of tritium. Anthropogenic sources include nuclear weapons testing, weapons manufacturing, operation of nuclear power plants (NPPs) and reprocessing of nuclear fuels. The average natural (or background) concentration of tritium in environmental waters has been estimated to range from $0.12 \mathrm{Bql}^{-1}$ to $0.9 \mathrm{Bql}^{-1}[1]$.

Although occurring naturally on Earth, significant amounts of tritium are also generated through human activity. For example, NPPs routinely (and sometimes accidentally) release tritium into the air and water. As no economically feasible technology currently exists to filter tritium from gaseous emissions and liquid effluents, routine releases and accidental spills are closely monitored. Most of the tritium that is released from NPPs end up in surface waters, which raises concerns regarding the potential for contamination of the drinking water. As nuclear reactors are usually located on rivers and/or lakes this concern is taken seriously. The expected tissue activity concentrations and relative biological effectiveness (RBE) of tritium are used to calculate the effective dose which in turn is used to evaluate if the exposure could be posing a health risk. Even in the absence of significant risks, international and national regulations require a constant control of tritium releases into the environment, especially into natural waters. Constant monitoring of the activity concentrations of tritium in surface waters is also required [2].

As tritium is a low energy beta-emitter (maximum energy $=18.6 \mathrm{keV}$ ), the common methods for low-level counting of tritium are either gas-proportional counting (GPC) or liquid scintillation counting (LSC). For analyzing natural water samples, it is more practical to use LSC because the water sample is simply combined with an aqueous scintillation cocktail and the counting efficiency is higher than that of GPC [3].

In this study, the water samples were taken from the Mlaka creek which passes through the site occupied by the Vinca Institute of Nuclear Science and Public company "Nuclear Facilities of Serbia" (PC NFS) in Belgrade, Serbia. The Mlaka creek is $5 \mathrm{~km}$ long with an average water flow of only $10 \mathrm{l} \mathrm{s}^{-1}$. Two out of the 3 sampling locations were situated near the discharge from research reactor RA. Increases in tritium activity concentrations can, therefore, be attributed to tritium liquid releases from the reactor target storage basins into the catchments area [3].

Surface water samples were taken monthly (during a four-month period in 2018) from three locations 
along the Mlaka creek, in the vicinity of the nuclear facilities (Figure 1).

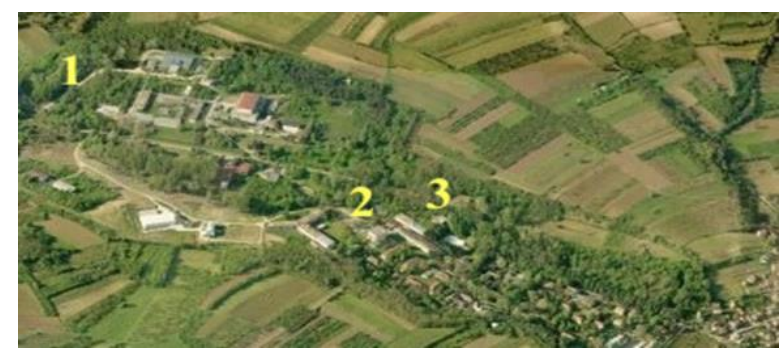

Figure 1. Sampling locations

The first sampling point is located upstream of the nuclear facilities. The other two sampling locations are on the nuclear facilities site.

\section{MATERIALS AND METHODS}

All samples were measured using a Quantulus 1220 liquid scintillation counter (LSC), which is a low-level background LSC manufactured by Perkin Elmer, Finland [4]. This instrument has its own background reduction system around the vial chamber, which consists of both an active and passive shield. The passive shield is made of lead, copper and cadmium and the active shield is based on a mineral oil scintillator. Low-activity materials were used in the construction of the Quantulus, so it is useful for measuring low-level radiation activity. The system is provided with two pulse analysis circuits that are accessible for the users: a pulse shape analysis (PSA) and pulse amplitude comparator (PAC) circuit. There is also a delayed coincidence circuit (DCOS) inside the Quantulus, which is useful for the correction of chemiluminescence. The Quantulus 1220 has two multichannel analyzers (MCA), one is used for active shield and the second one is used for spectra record. Those MCA's are divided in two halves, 1024 channels each. The tritium configuration of the MCA's setting eliminates the random noise of phototubes, inhibits the coincidence pulse from the guard and the sample, and monitors the random coincidence by DCOS in a half of the MCA, the whole sample spectrum being recorded in the other half of the MCA. Quenching was quantified with the external standard quenching parameter, SQP(E), which was used to determine the counting efficiency of the system with appropriate calibration curves [5].

An ASTM method for sample distillation [6] was used to prepare the samples [3]-[7]. A $100 \mathrm{ml}$ drinking water sample aliquot was treated with $0.5 \mathrm{~g}$ of sodium hydroxide and $0.1 \mathrm{~g}$ of potassium permanganate (the alkaline treatment is to prevent other radionuclides such as radioiodine and radiocarbon from distilling over with the tritium, the permanganate treatment is to oxidize trace organics that could cause quenching interferences). The middle fraction of the distillate was collected for tritium analysis (early and late fractions are more apt to contain interfering materials and were therefore discarded). The collected distillate fraction was thoroughly mixed and a portion (up to $10 \mathrm{ml}$ ) was mixed with LS cocktail (8:12 sample to cocktail ratio).
After leaving the mixture for 6 hours in the dark, in the counting room, to allow it to equilibrate and reach room temperature, the beta emissions were counted by LSC.

Calibration of LS counter assumed preparation of the following samples:

- RWTS - raw water tritium solution: tritium standard solution added to un-distilled background raw water (RW)

- DRW - distilled tritium-free raw water, used for background determination

- DWTS - distilled water tritium standard solution: RW was distilled and a tritium standard solution was added so that the tritium activity concentration was equal to the one in RWTS

- DRWTS - distilled raw water tritium standard: RWTS treated with sodium hydroxide and potassium permanganate, and distilled afterwards (first $10 \mathrm{ml}$ of distillate was discarded and then the middle distillate was collected)

Three aliquots of DRWTS, DWTS and DRW were prepared, mixed with LS cocktail in polyethylene $20 \mathrm{ml}$ vials (PE vials), dark-adapted and counted on the Quantulus LSC. Obtained count rates were $R_{\text {DRWTS }}\left[\mathrm{s}^{-1}\right], R_{\text {DWTS }}\left[\mathrm{s}^{-1}\right]$ and $R_{\mathrm{DRW}}\left[\mathrm{s}^{-1}\right]$, respectively.

The detection efficiency was calculated as follows:

$$
\varepsilon=\frac{R_{\mathrm{DWTS}}-R_{\mathrm{DRW}}}{A_{\mathrm{DWTS}}},
$$

where $A_{\text {DWTS }}[\mathrm{Bq}]$ was the activity of DWTS.

The recovery correction factor, $F$, was obtained as:

$$
F=\frac{R_{\mathrm{DRWTS}}-R_{\mathrm{DRW}}}{\varepsilon A_{\mathrm{RWTS}}},
$$

where $A_{\text {RWTS }}[\mathrm{Bq}]$ was the activity of RWTS.

The tritium activity concentration of analyzed sample, $A\left[\mathrm{~Bq} \mathrm{l}^{-1}\right]$, was calculated as:

$$
A=\frac{R_{\mathrm{S}}-R_{\mathrm{DRW}}}{\varepsilon F V e^{-\lambda t}}
$$

where $R_{\mathrm{S}}\left[\mathrm{s}^{-1}\right]$ was the sample's aliquot gross count rate, $V[1]$ was the sample volume, $\lambda\left[\mathrm{d}^{-1}\right]=\frac{\ln 2}{t_{1 / 2}}$ was the decay constant for tritium, $t_{1 / 2}=4500 \mathrm{~d}$ is the half-life of tritium, $t[\mathrm{~d}]$ was the elapsed time between sampling and counting.

The critical activity concentration, $L_{C}\left[\mathrm{~Bq} \mathrm{l}^{-1}\right]$, was calculated for each sample as follows:

$$
L_{C}=\frac{1.65 \sqrt{R_{\mathrm{DRW}} t_{\mathrm{S}}\left(1+\frac{t_{\mathrm{S}}}{t_{\mathrm{DRW}}}\right)}}{\varepsilon t_{\mathrm{S}} F V e^{-\lambda t}},
$$

where $t_{\mathrm{S}}[\mathrm{s}]$ and $t_{\mathrm{DRW}}[\mathrm{s}]$ were the counting times of the sample and background, respectively. The measured activity concentration, was compared to $L_{C}$ to determine whether tritium was clearly present in the sample. When the detection criterion was used, a priori minimum detectable activity concentration, $M D A\left[\mathrm{~Bq} \mathrm{l}^{-1}\right]$, was determined as:

$$
M D A=\frac{2.71+3.29 \sqrt{R_{\mathrm{DRW}} t_{\mathrm{S}}\left(1+\frac{t_{\mathrm{S}}}{t_{\mathrm{DRW}}}\right)}}{\varepsilon t_{\mathrm{S}} F V e^{-\lambda t}}
$$


Figure of merit, $F O M$, was used as the evaluation parameter of the method's performance:

$$
F O M[s]=\frac{\varepsilon^{2}}{R_{D R W}\left[s^{-1}\right]}
$$

Low diffusion polyethylene $20 \mathrm{ml}$ vials were used because of their lowest background level and all samples were dark adapted for 6 hours before counting. The cocktail performance (distillation method for $3 \mathrm{H}$ determination, PE vials, 8:12 sample: cocktail ratio) is presented in Table 1 . The default MCA tritium configuration of the WinQ software was used for the measurements asit eliminated noise from the photomultiplier tubes as well as the coincident signals from the shield and sample.

Table 1. Cocktail performance for $3 \mathrm{H}$ determination

\begin{tabular}{|l|c|c|c|c|}
\hline $\begin{array}{l}\text { Scintillation } \\
\text { cocktail }\end{array}$ & $\begin{array}{c}\text { Blank } \\
{\left[\mathrm{s}^{-1}\right]}\end{array}$ & $\begin{array}{c}\text { Efficiency } \\
{[\%]}\end{array}$ & $\begin{array}{c}\text { Recovery } \\
\text { factor }\end{array}$ & $\begin{array}{c}\text { MDA } \\
{\left[\mathrm{Bq} \mathrm{l} \mathrm{l}^{-1}\right]}\end{array}$ \\
\hline $\begin{array}{l}\text { UltimaGold } \\
\text { LLT }\end{array}$ & 0.023 & $35.8(7)$ & 0.9891 & 2.2 \\
\hline
\end{tabular}

\section{RESUlTS AND DisCUSSION}

The results obtained for the surface water samples taken from three different locations along the Mlaka creek, during the period January - April 2018 are presented in Table 2.

Table 2. Tritium activity concentrations in water samples

\begin{tabular}{cccc}
\hline Surface & \multicolumn{3}{c}{ Locations } \\
\cline { 2 - 4 } water & Point 1 & Point 2 & Point 3 \\
\hline Month & 3 H Activity concentrations [Bq/1] \\
\hline January & $3.3 \pm 0.8$ & $18.6 \pm 1.4$ & $14.5 \pm 0.3$ \\
February & $<2.2$ & $9.6 \pm 0.9$ & $5.7 \pm 1.1$ \\
March & $<2.2$ & $7.3 \pm 0.8$ & $4.8 \pm 0.7$ \\
April & $2.2 \pm 0.8$ & $6.1 \pm 0.3$ & $5.7 \pm 0.6$ \\
\hline
\end{tabular}

In this paper, we used a counting time of 300 minutes and got a MDA value of $2.2 \mathrm{Bql}^{-1}$. The determined detection efficiency was $(35.8 \pm 0.7) \%$, Table 1.

According to the European Commission, the action level for tritium in water is $100 \mathrm{Bql}^{-1}$. This value is not based on health effects relative to its consumption but is rather a monitoring guideline.

Tritium concentrations in Mlaka creek ranged from MDA to $18.6 \mathrm{Bql}^{-1}$. The values of tritium activity concentration for the first sampling point on the Mlaka creek (upstream of nuclear facilities) were below or around the MDA value, and water samples collected at the other sampling locations showed slightly higher $3 \mathrm{H}$ activity concentrations, which can be attributed to the influence of the heavy water nuclear reactor RA located in PC NFS.

\section{CONCLUSION}

In this paper, we presented water tritium activity concentration results obtained from Mlaka creek. The water samples were collected at the PC NFS site over a four-month period (between January and April 2018). Tritium activity concentrations ranged from 2.2 to 18.6 $\mathrm{Bql}^{-1}$, which is consistent with reported annual tritium levels.

Although the stated activity concentrations are far below the action level for tritium in water, it is essential to continuously monitor the tritium level near nuclear facilities.

Acknowledgements: The authors acknowledge the financial support of the Provincial Secretariat for Higher Education and Scientific Research within the project "Radioactivity in drinking water and cancer incidence in Vojvodina" no. 114-451-2405/2016, and the Ministry of Education, Science and Technological Development of the Republic of Serbia within projects no. OI171002, III43002.

\section{REFERENCES}

1. The European Commission. (Nov. 3, 1998). Council Directive 98/83/EC of 3 Nov. 1998 on the quality of water intended for human consumption.

Retrieved from: https://eur-lex.europa.eu/legalcontent/EN/TXT/PDF/?uri=CELEX:31998L0083\&f rom=EN;

Retrieved on: May 16, 2018

2. J. Nikolov et al., "Tritium in Water: Hydrology and Health Implications," in Tritium Advances in Research and Applications, M. Janković, Ed., New York (NY), USA: Nova Science Publishers, 2018, ch. 5, pp. $157-213$.

3. J. Nikolov et al., "Different methods for tritium determination in surface water by LSC," Appl. Radiat. Isot., vol. 71, no. 1, pp. 51 - 56, Jan. 2013.

DOI: 10.1016/j.apradiso.2012.09.015

PMid: 23085734

4. 1220 Quantulus Ultra Low Level Liquid Scintillation Spectrometer, PerkinElmer Life and Analytical Sciences, Shelton (CT), USA, 2005.

Retrieved from: https://www.perkinelmer.com.cn/C MSResources/Images/4673870SPC 1220Quantulus.pdf; Retrieved on: May 16, 2018

5. I. Stojković et al., "Methodology of tritium determination in aqueous samples by liquid scintillation counting techniques," in Tritium Advances in Research and Applications, M. Janković, Ed., New York (NY), USA: Nova Science Publishers, 2018, ch. 4, pp. $99-157$.

6. Standard Test Method for Tritium in Drinking Water, ASTM D 4107-08, Jun. 15, 2013.

DOI: 10.1520/D4107-08R13

7. I. Jakonić et al., "Optimization of low-level LS counter Quantulus 1220 for tritium determination in water samples," Radiat. Phys. Chem., vol. 98, pp. 69 - 76, May 2014.

DOI: 10.1016/j.radphyschem.2014.01.012 